\title{
Differences in Bulk Damage Probability Distributions between Tripler and Z-Cuts of KDP and DKDP at $355 \mathrm{~nm}$
}

\author{
M. Runkel, A. K. Burnham
}

This article was submitted to $32^{\text {nd }}$ Annual Symposium on Optical Materials for High Power Lasers Boulder, $\mathrm{CO}$ October 16-18, 2000

Lawrence Livermore National Laboratory
December 11, 2000 


\section{DISCLAIMER}

This document was prepared as an account of work sponsored by an agency of the United States Government. Neither the United States Government nor the University of California nor any of their employees, makes any warranty, express or implied, or assumes any legal liability or responsibility for the accuracy, completeness, or usefulness of any information, apparatus, product, or process disclosed, or represents that its use would not infringe privately owned rights. Reference herein to any specific commercial product, process, or service by trade name, trademark, manufacturer, or otherwise, does not necessarily constitute or imply its endorsement, recommendation, or favoring by the United States Government or the University of California. The views and opinions of authors expressed herein do not necessarily state or reflect those of the United States Government or the University of California, and shall not be used for advertising or product endorsement purposes.

This is a preprint of a paper intended for publication in a journal or proceedings. Since changes may be made before publication, this preprint is made available with the understanding that it will not be cited or reproduced without the permission of the author.

This report has been reproduced directly from the best available copy.

Available electronically at http://www.doc.gov/bridge

Available for a processing fee to U.S. Department of Energy

And its contractors in paper from

U.S. Department of Energy

Office of Scientific and Technical Information

P.O. Box 62

Oak Ridge, TN 37831-0062

Telephone: (865) 576-8401

Facsimile: (865) 576-5728

E-mail: reports@adonis.osti.gov

Available for the sale to the public from

U.S. Department of Commerce

National Technical Information Service

5285 Port Royal Road

Springfield, VA 22161

Telephone: (800) 553-6847

Facsimile: (703) 605-6900

E-mail: orders@ntis.fedworld.gov

Online ordering: http:/ / www.ntis.gov/ordering.htm

\section{OR}

Lawrence Livermore National Laboratory

Technical Information Department's Digital Library

http: / / www.llnl.gov/tid/Library.html 


\title{
Differences in bulk damage probability distributions between tripler and z-cuts of KDP and DKDP at $355 \mathrm{~nm}$
}

\author{
Mike Runkel ${ }^{*}$ and Alan K. Burnham \\ Lawrence Livermore National Laboratory, Livermore, CA 94550
}

\begin{abstract}
Over the course of testing a substantial number of KDP and DKDP crystals from rapid and conventional growth processes, we have discovered that there is a consistent difference in the value of the damage resistance between $\mathrm{z}$-cut and tripler, $\mathrm{x}$-cut and $\mathrm{y}$-cut crystals for a given test fluence. This increase in damage probability for tripler, $\mathrm{x}$ and $\mathrm{y}$-cut crystals is consistent for both conventional and rapid growth KDP as well as DKDP. It also holds for unconditioned (S/1) and conditioned (R/1) tests and has values of $2.1 \pm 0.6$ and $1.5 \pm 0.3$ respectively. Testing has also revealed that there is no sensitivity to incident laser polarization. This is in direct contradiction to models based on simple, non-spherical absorbers. This result plus new information on the size and evolution of bulk damage density (see Runkel et al., this proceedings) has led to a reinterpretation of the growth parameter data for rapid growth NIF boules. It now appears that variations in impurity concentration throughout the boule do not affect the damage probability curve as dramatically as previously thought; although, this is still a topic of intensive investigation.
\end{abstract}

Keywords: KDP, DKDP, laser damage, triple harmonic generation

\section{INTRODUCTION}

Development of KDP and DKDP crystals for use on the National Ignition Facility (NIF) has required extensive testing to map the effects of growth parameter variation on the damage performance of the crystals. The parameter space we are mapping is quite large and encompasses the purity of the starting salt, impurity dissolution and uptake from the tanks, rate of solution filtration, the role of growth temperature, platform shape, rotation rates and direction of growth (horizontal or vertical), degree of deuteration and so on. The parameter space is enlarged considerably when post-growth treatments such as thermal annealing and laser conditioning are considered.

Until recently, most damage tests were performed on samples taken from rapidly grown boules produced in small (20 liter) tanks. The samples usually taken from these boules were z-plates, or plates perpendicular to the optic axis of the crystal (see Figure 1). A combination of factors was responsible for this choice including the size limitations on the boule, easily locatable sector boundaries and turnaround time considerations in the growth/test feedback cycle. Despite the fact that largetank boules have been under development since 1997, it was not until the past year that large numbers of samples became available from an increasing number of NIF-sized, rapid growth boules, and the shift towards fabricating tripler-cut damage samples began in earnest. During this phase of development testing, we began to see a number of unusual test results where the damage curve from one or two samples would deviate significantly from others in the boule. Initially, much time was spent examining the Zeus damage tester for calibration anomalies. When none were found, we attempted to correlate the damage curves with the impurity level of the samples by their growth time and location (prismatic or pyramidal material.) At this time we were concentrating heavily on the possibility that $\mathrm{FePO}_{4}$ nanoclusters were the damage initiator, and the uptake of impurities in the boule played a central role in these considerations. However, this approach was not very fruitful either. (This rather extensive topic will be the subject of a future report, so we will not discuss the role of impurities here in any great detail.) By this time we had tested enough z- and tripler cut material from both small and large-tank, rapid-growth samples so that we noticed a consistent difference between these two types of samples. Over the course of additional testing, we have discovered that THG plates typically exhibit a $\sim 50$ percent lower damage probability curve for both the unconditioned $(\mathrm{S} / 1)$ and conditioned $(\mathrm{R} / 1)$ tests, and this difference applies to both KDP and DKDP, whether rapidly or conventionally grown. 
The remaining sections of this paper describe the differences between tripler cuts and z-cuts from small and large-tank, rapidgrowth, KDP and DKDP crystals as well as conventional-growth KDP and DKDP samples.

In addition, Yoshida et al. ${ }^{2}$ have recently published results of a similar study on conventional-growth KDP. In section 3, we compare our results to theirs, and note some differences that may be accounted for by apparatus and test techniques.

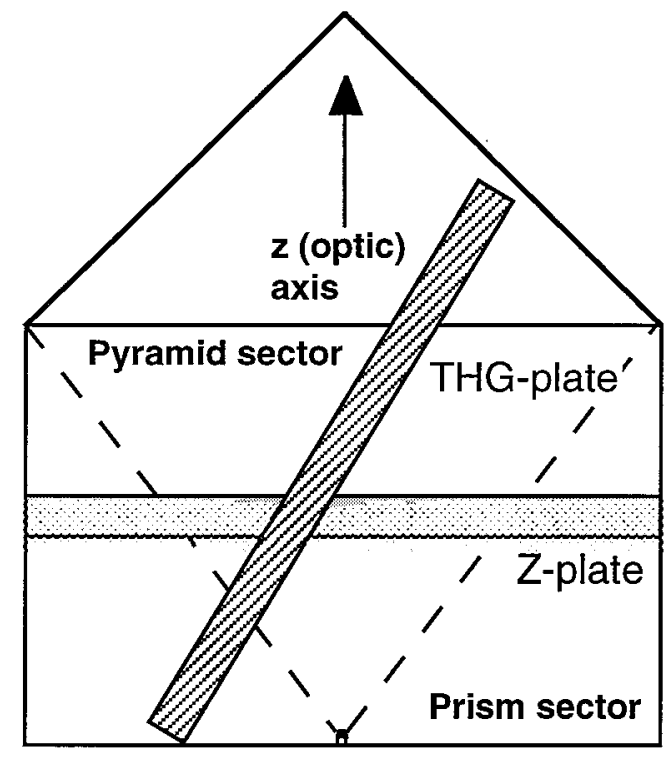

Side view, vertical growth boule

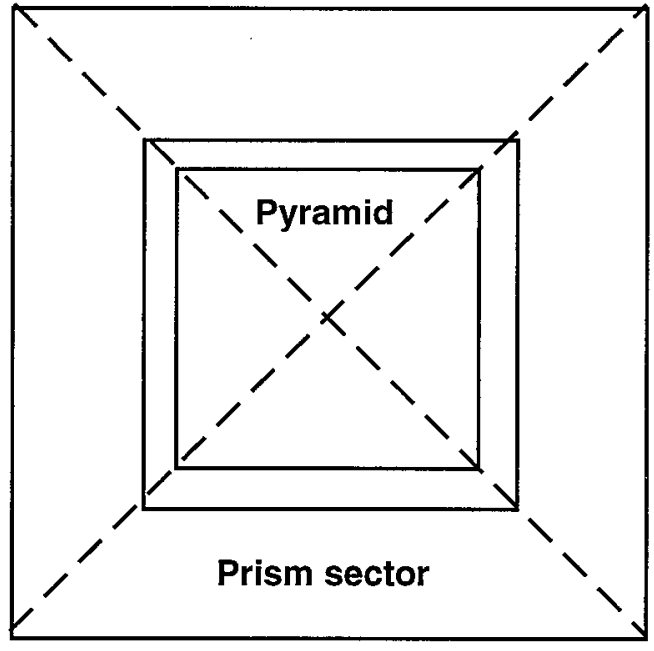

Z-plate, top view

Figure 1. Schematic of a vertical growth DKDP/KDP boule showing the sector boundaries found in a z-plate (Figure $1 \mathrm{~b}$ ). The sector boundaries found in a tripler can vary significantly depending on where the sample was taken from the boule.

\section{EXPERIMENTAL DATA}

\subsection{Zeus damage tests}

Almost all of the testing discussed in this report was done at $355 \mathrm{~nm}(3 \omega)$ and $7.6 \mathrm{~ns}$ with the Zeus automated damage test (ADT) system ${ }^{1}$. The beam on the sample was $\sim 0.7 \mathrm{~mm}\left(\mathrm{FW} @ 1 / \mathrm{e}^{2}\right.$ ) and was linearly polarized. A half-waveplate was installed in the beam to rotate the polarization as desired during the course of testing. All samples were tested at near-normal incidence ( $\sim 1-2$ degrees).

Standard unconditioned $(\mathrm{S} / 1)$ and conditioned $(\mathrm{R} / 1)$ tests were performed on all of the $\mathrm{z} /$ tripler cut sample sets in some combination. The $\mathrm{S} / 1$ test consisted of exposing ten sites to a fixed fluence for duration of up to 30 seconds ( 300 shots) and recording the percentage of sites that failed. A range of fluences separated into $\sim 15 \%$ intervals were used to cover the failure percentages (or probabilities) from zero to $100 \%$. Thus each complete damage probability curve typically took on the order of 40-70 sites to map out. In contrast, the $\mathrm{R} / 1$ (or conditioned) curve was generated by exposing at least 50 individual test sites to fluence ramps of $\sim 0.5 \mathrm{~J} / \mathrm{cm}^{2} / \mathrm{s}$ until failure was observed. The cumulative failure probability was then determined from the ensemble of individual damage thresholds.

\subsection{Optical Sciences Laser damage tests}

Two samples from large-tank, rapid-growth, boule BD7 were also tested using the 100-J Optical Sciences Laser (OSL) in the configuration reported in reference 6. This was done to be certain the tripler/ $z$ effect was not an artifact of the Zeus ADT system. We describe the results of these tests in section 2.3.2. 


\subsubsection{Small tank, rapid-growth boules}

The matrix of samples tested for the tripler/z effect consisted primarily of DKDP samples. This matrix was intended to evaluate a wide variety of growth parameters. This series of boules revealed that the crystals grown at lower temperature range was consistently higher in damage resistance. Consequently, Figure 2 shows the difference between tripler and zplates for low and high temperature, small tank crystals. We discuss the effect of growth temperature on damage performance in a separate report to be published in these proceedings ${ }^{5}$.
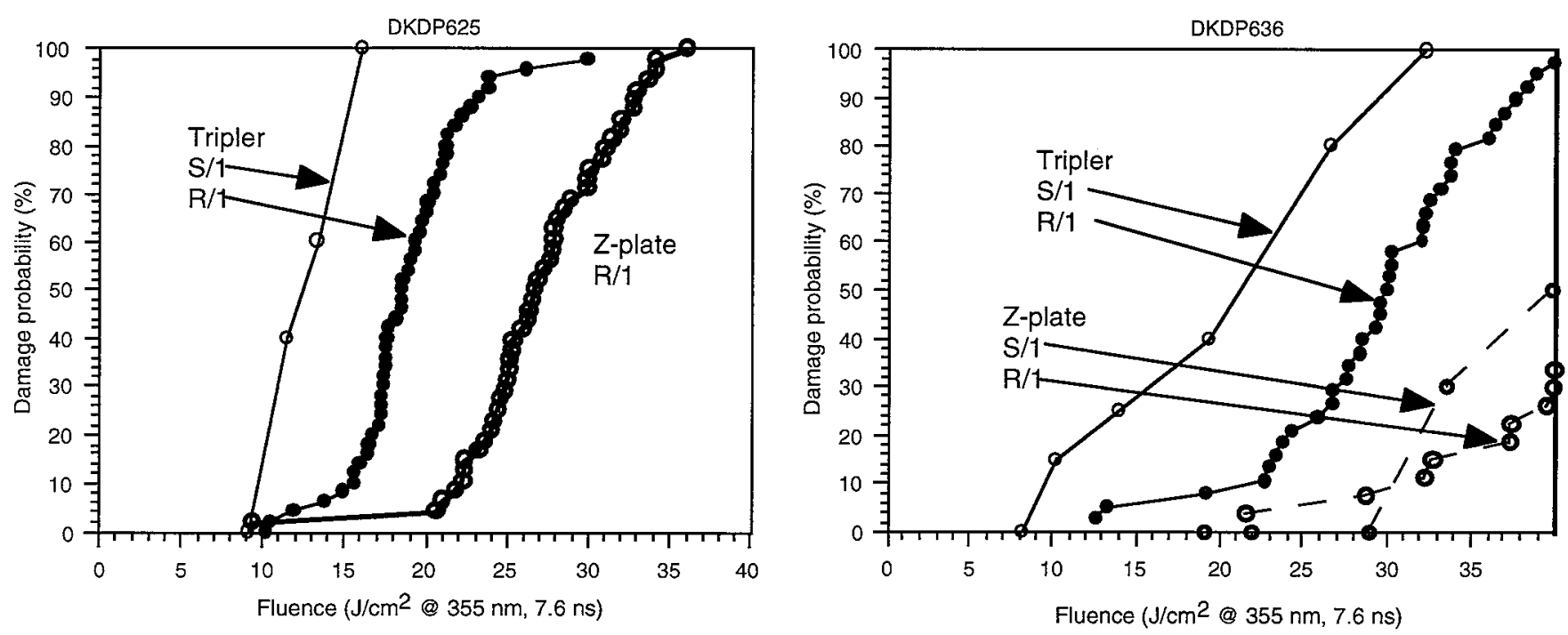

Figure 2. S/1 and R/1 damage probability curves for small tank, rapid-growth crystals DKDP625 and DKDP636. DKDP625 was grown at higher temperature $\left(61-48^{\circ} \mathrm{C}\right)$ than DKDP636 $\left(42-28^{\circ} \mathrm{C}\right)$.

Considering the change in the $50 \%$ damage probability fluence as a measure of performance, DKDP 625 shows a reduction between the z-cut and tripler of $30 \%$. The $\mathrm{S} / 1$ test on the z-plate has not been done. DKDP636 represents the class of crystals with ultrahigh damage performance. The data for the z-plate is among the highest of any crystal tested, whether conventional or rapid growth. Obtaining a statistically valid data set for bulk damage in the z-plate was difficult as surface damage began to become prevalent, especially for the R/1 tests. Nonetheless, this type of crystal represents the quality needed to meet the NIF obscuration specification for triplers without laser conditioning.

\subsubsection{Large tank, rapid-growth boules}

To date we have tested tripler, $x$-cuts and $z$-cuts from a number of large-tank (1000 liters), rapid-growth boules including RG8A (RGA8), AD-16, BD-5, BD-7 and CD-35. Of this set of boules, all were grown vertically with the exception of AD16 and CD-35, which were grown horizontally. The tripler/z effect was found in all of these boules. The data for BD-7 is indicative of the type of performance of these boules. Figure 3 shows R/1 damage curves for tripler and $\mathrm{z}$-cuts as well as a map of the boule showing sample locations. 

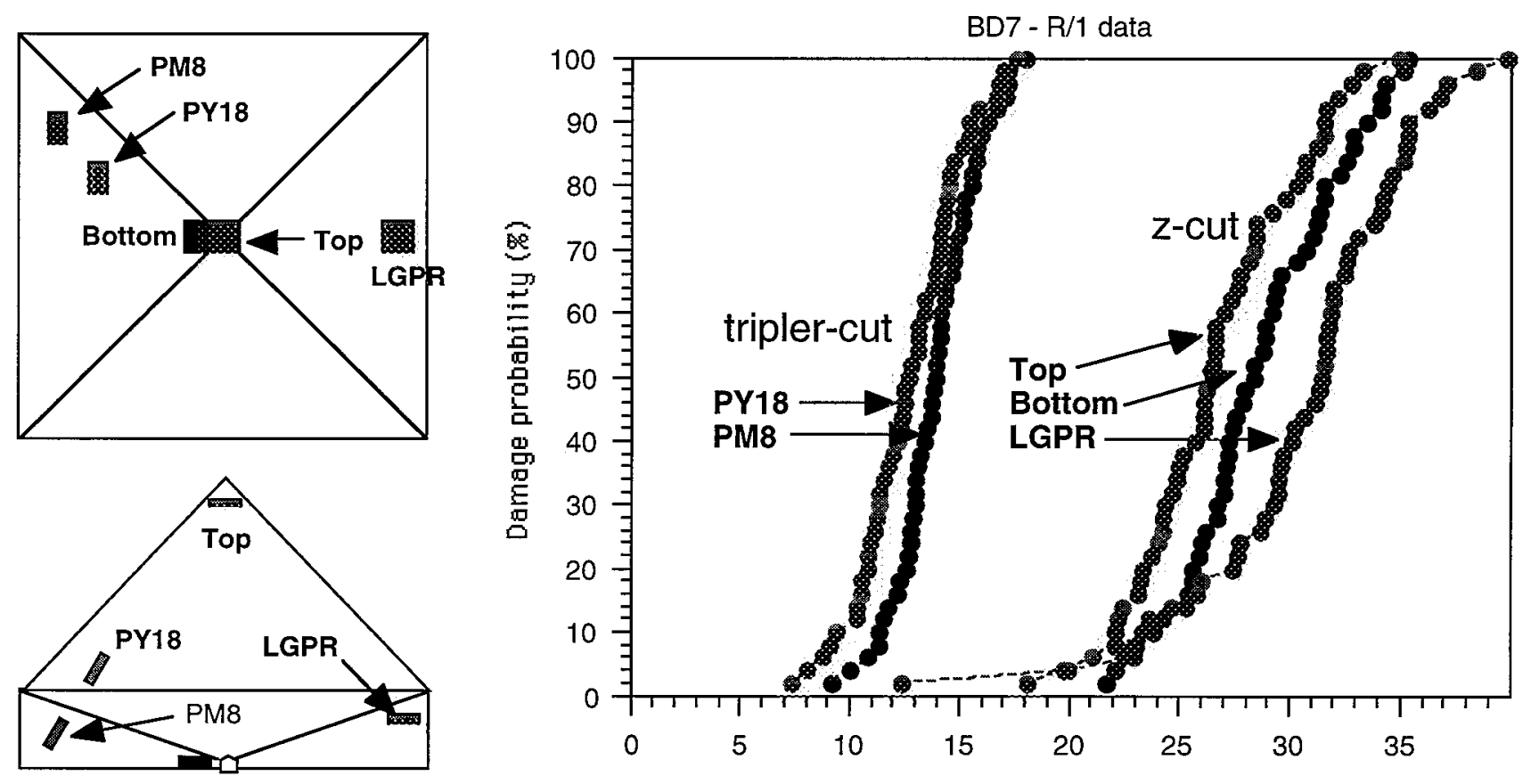

Fluence (J/cm2 @ $355 \mathrm{~nm}, 7.6 \mathrm{~ns})$

Figure 3. BD-7 boule map showing approximate locations of damage samples and their associated R/1 damage curves. Despite the wide variation of impurities in each sample (due to location), the curves for each cut are similar but the THG-cut is substantially lower than the $z$-cut. The $\pm 15 \%$ fluence error bar is not shown on the damage curves.

The samples shown in Figure 3 came from a wide variety of locations within the boule. Based on impurity analysis of other large boules, we can expect that the impurity levels (iron, aluminum, barium, chromium, etc.) for the $B D-7$ Bottom sample reflects the impurities present in the starting solution, because it represents growth from the first several days of the run. This sample was cut in the prism very near the seed. BD-7 Top, on the other hand, represents the most pure material in the boule. This is because the boule has reached a size where the prism sector has absorbed more impurities than are leached into the solution from the tank wall and because pyramid material rejects most ions found in the growth solution. Despite the potential difference in impurity concentration, these samples exhibit the same damage performance. In addition, the damage curve for last grown prism sample, BD-7 LGPR, is slightly better than either BD-7 Top or Bottom. This sample can be expected to have impurity levels comparable to BD-7 Bottom.

Examination of the boule map and damage curves for the tripler samples does not show a dependence on impurity level. Based on approximate location, these samples were taken at similar growth times from prism and pyramidal sectors. Therefore, we can expect that the prism sample (PM8) will have substantially higher ionic impurities than the pyramidal sample (PY18), yet their damage curves are statistically the same. To be certain that these results were not somehow due large variations in impurity levels among the samples, we fabricated a large, multifaceted sample from the pyramidal sector of the boule. This sample was cut with tripler, $\mathrm{x}$ - and $\mathrm{z}$ - faces. $\mathrm{S} / 1$ tests were then performed on the sample and the results are shown in Figure 4. Here again, we see the large difference between the tripler and $z$ - faces. In addition, the $x$-cut shows the same damage curve as the tripler. 

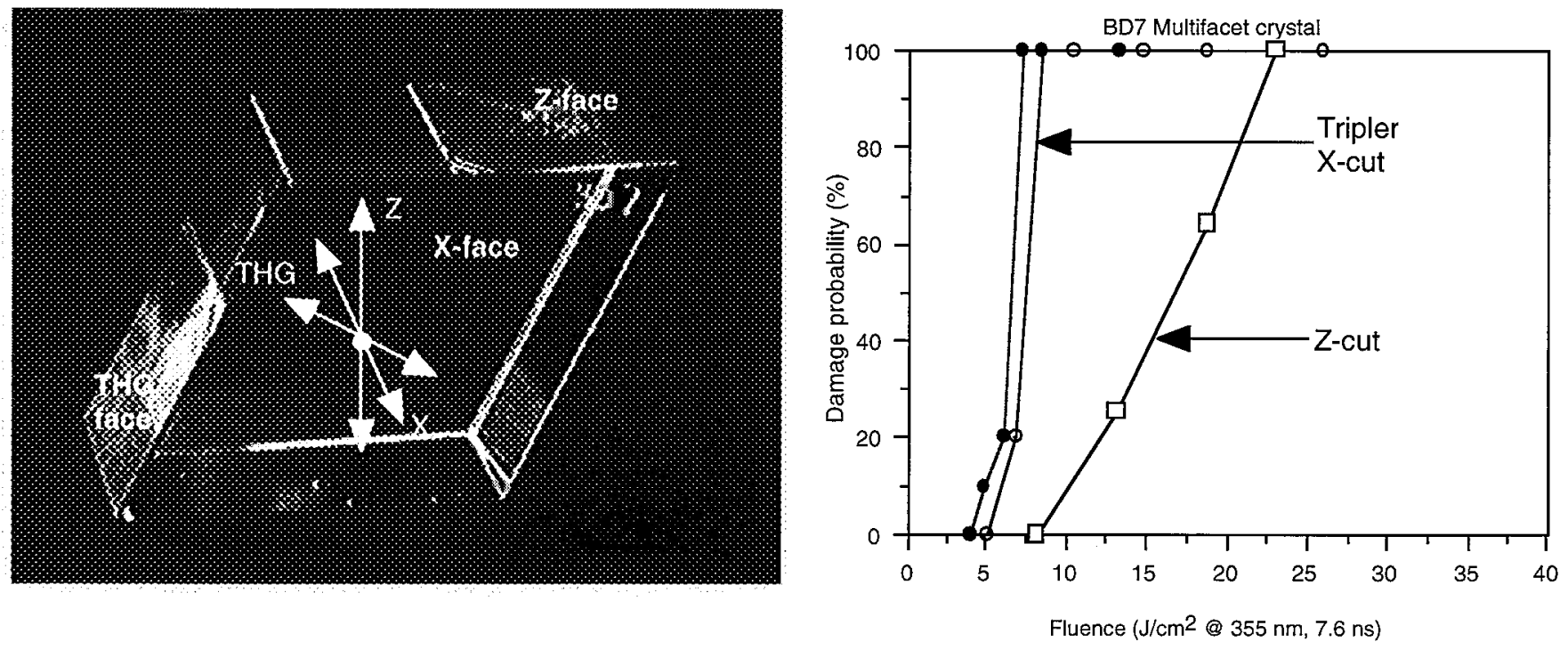

Figure 4. Photograph of multifaceted sample from BD-7 and the associated S/1 damage curves from the tripler, $x-$ and $z-$ faces. $\mathrm{R} / 1$ tests were not performed because we could not get the detection diagnostic to work on all faces with equal sensitivity.

To assure that the differences in damage curves were not the result of some unknown detection anomaly of the Zeus damage test system, we tested a z-cut (BD-7 LGPR) and tripler cut (BD-7 PY11) on OSL. The samples were tested with nominally identical conditions, under vacuum using a $10-\mathrm{ns}$ pulse duration at $351 \mathrm{~nm}$. The average fluence on each site was approximately $9 \mathrm{~J} / \mathrm{cm}^{2}$. This resulted in a substantial difference in the level of damage. The z-plate suffered almost no damage while the tripler contains much higher levels of pinpoint density. This is shown in Figure 5.
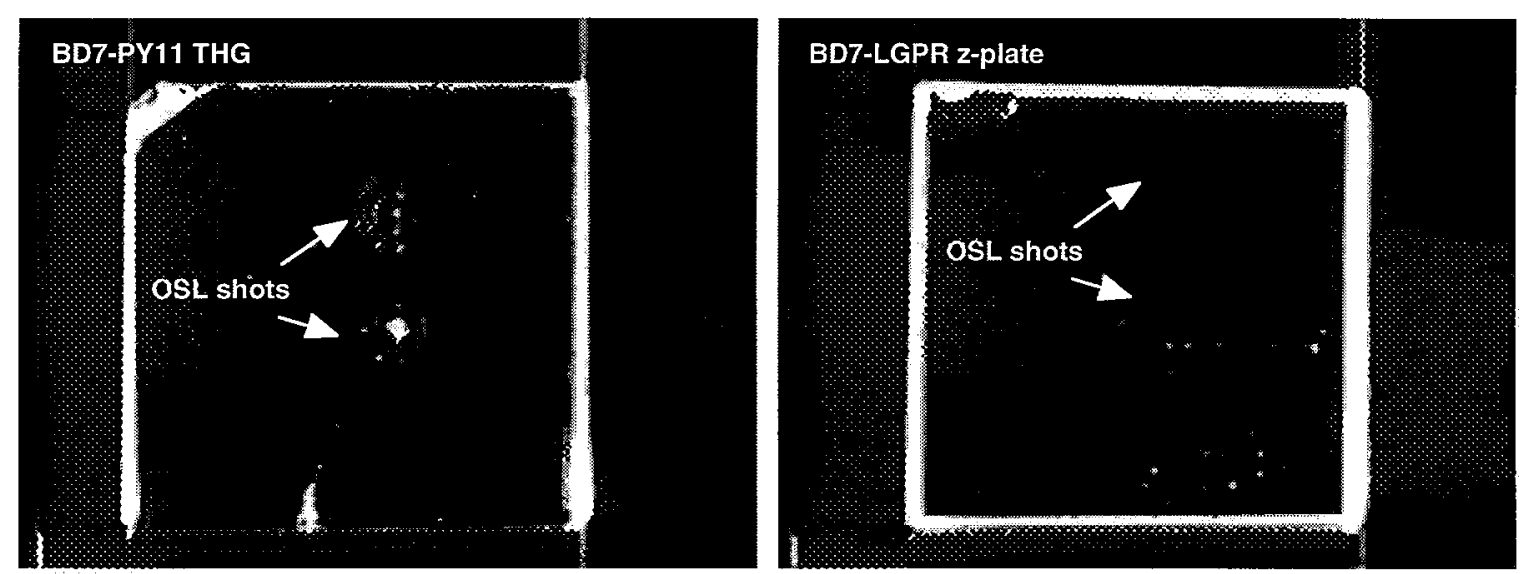

Figure 5. Darkfield images of BD-7 z-plate and tripler cut crystals shot on OSL at $351 \mathrm{~nm}, 10 \mathrm{~ns}$ with average beam fluence of $\sim 9 \mathrm{~J} / \mathrm{cm}^{2}$. The z-plate suffered almost no damage at this fluence while the tripler has enough damage to easily be seen in the image.

To account for the observed anisotropy between tripler and z-cuts, an absorption model based on non-spherical absorbers was proposed. Such a model naturally incorporates a dependence on the polarization state of the damage laser. To check this possibility, a number of damage curves with different plane polarizations were measured on various crystals. Only $S / 1$ tests of tripler-cut, pyramidal sample BD-7 PY15 are presented here. Two tests were conducted: the first with the laser's polarization parallel to the projection of the optic-axis of the crystal, i.e. the extraordinary direction, and the second test with the sample rotated to the ordinary orientation. The results are shown in Figure 6. No polarization dependence was observed. 


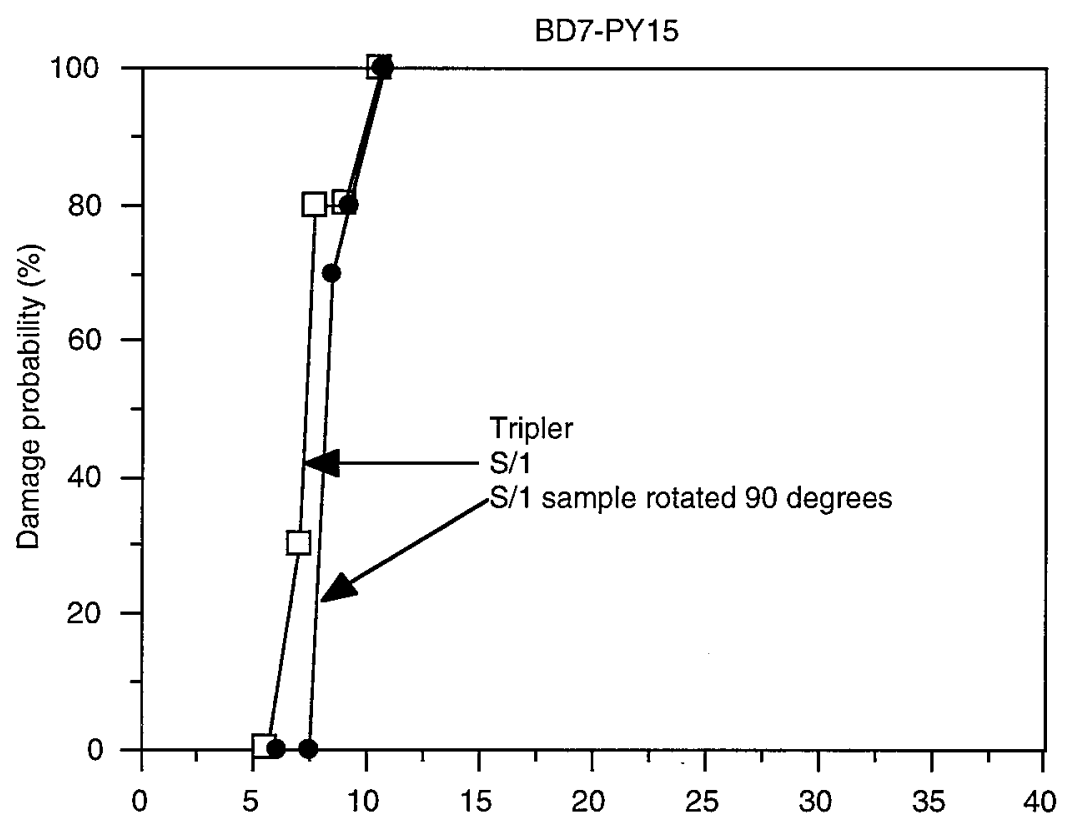

Fluence $\left(\mathrm{J} / \mathrm{cm}^{2} @ 355 \mathrm{~nm}, 7.6 \mathrm{~ns}\right)$

Figure 6. S/1 test results for BD-7 PY15, tripler sample showing that laser polarization does not affect the damage probability.

Coincident with the fabrication of the BD-7 multifacet crystal, we also had 7 sets of tripler, $\mathrm{x}$ - and $\mathrm{z}$-cut damage test samples (21 total) made from the horizontal growth, DKDP boule CD-35. Each set of crystals was cut from material spanning the growth history of the prism and pyramidal sectors, and the 3 cuts from each set were positioned to be as close together as possible. The intent was first to eliminate any effects of impurity concentration associated with growth time and sector for each set of crystals, and second to determine if damage performance changed with position in the boule. Figure 7 shows the boule map.

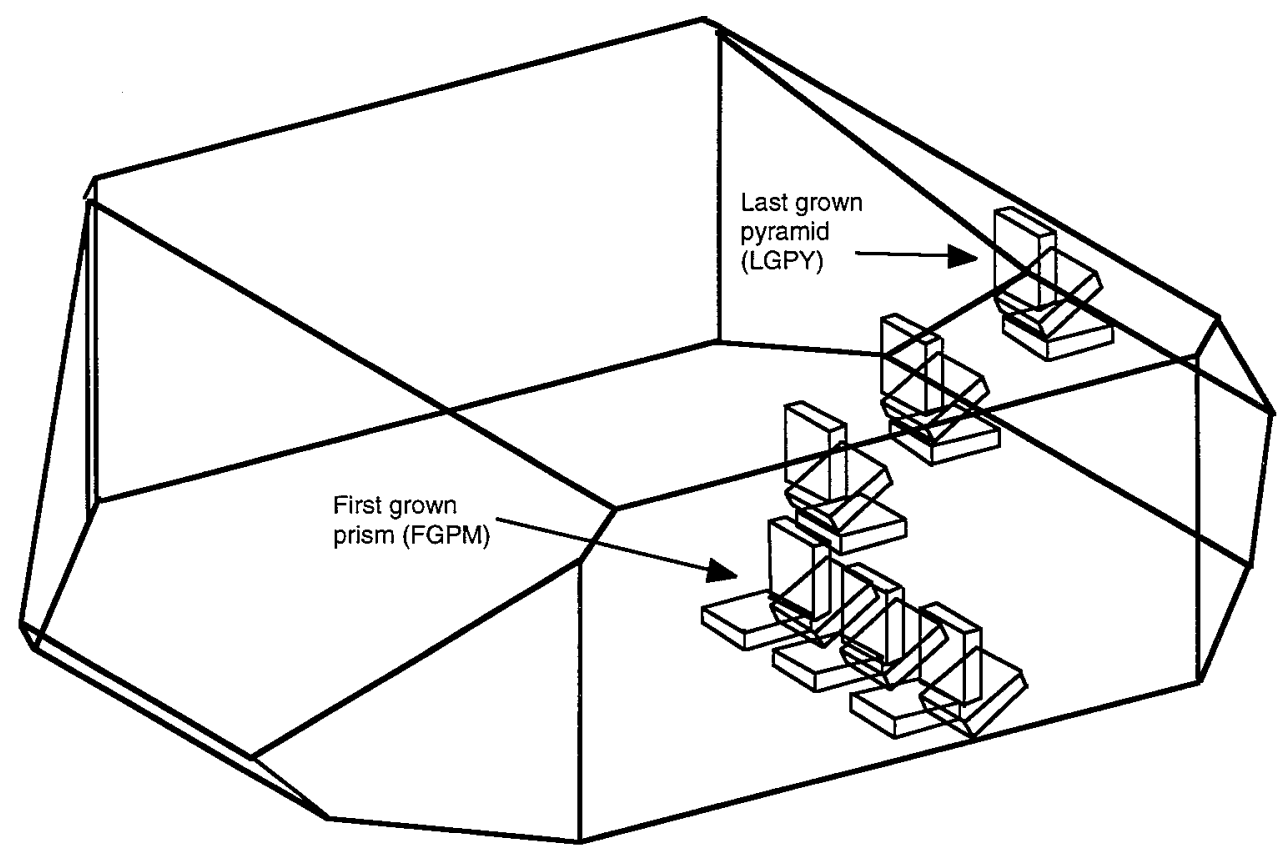

Figure 7. Boule map for horizontal rapid growth boule CD35 that shows the location of the first grown prism (FGPM) and last grown pyramid (LGPY) $\mathrm{x}$-, tripler and $\mathrm{z}$-cuts. 
This set of samples was also used to make a more thorough examination of the polarization dependence of damage. Prior to testing, a half waveplate was installed in the damage beam to control the laser polarization relative to the optic axis (or its projection). $S / 1$ and $R / 1$ tests were performed on the tripler and $x$-cuts of the first grown prism (FGPM) samples. Laser polarizations of $0^{\circ}$ (parallel to the optic axis projection in the crystal), $45^{\circ}, 90^{\circ}$ (perpendicular to the optic axis projection) and $135^{\circ}$ were used in testing for a total of 8 tests on each crystal. The FGPM z-plate could not be tested this extensively because it contained a high density of inclusions through most of the sample. (Only a single S/1 test was performed on it, however it was substantially better than either the x-or tripler cuts.) The conclusion from all this testing is that there is no sensitivity to polarization in either $\mathrm{S} / 1$ of $\mathrm{R} / 1$ cases. This is shown in Figure 8.
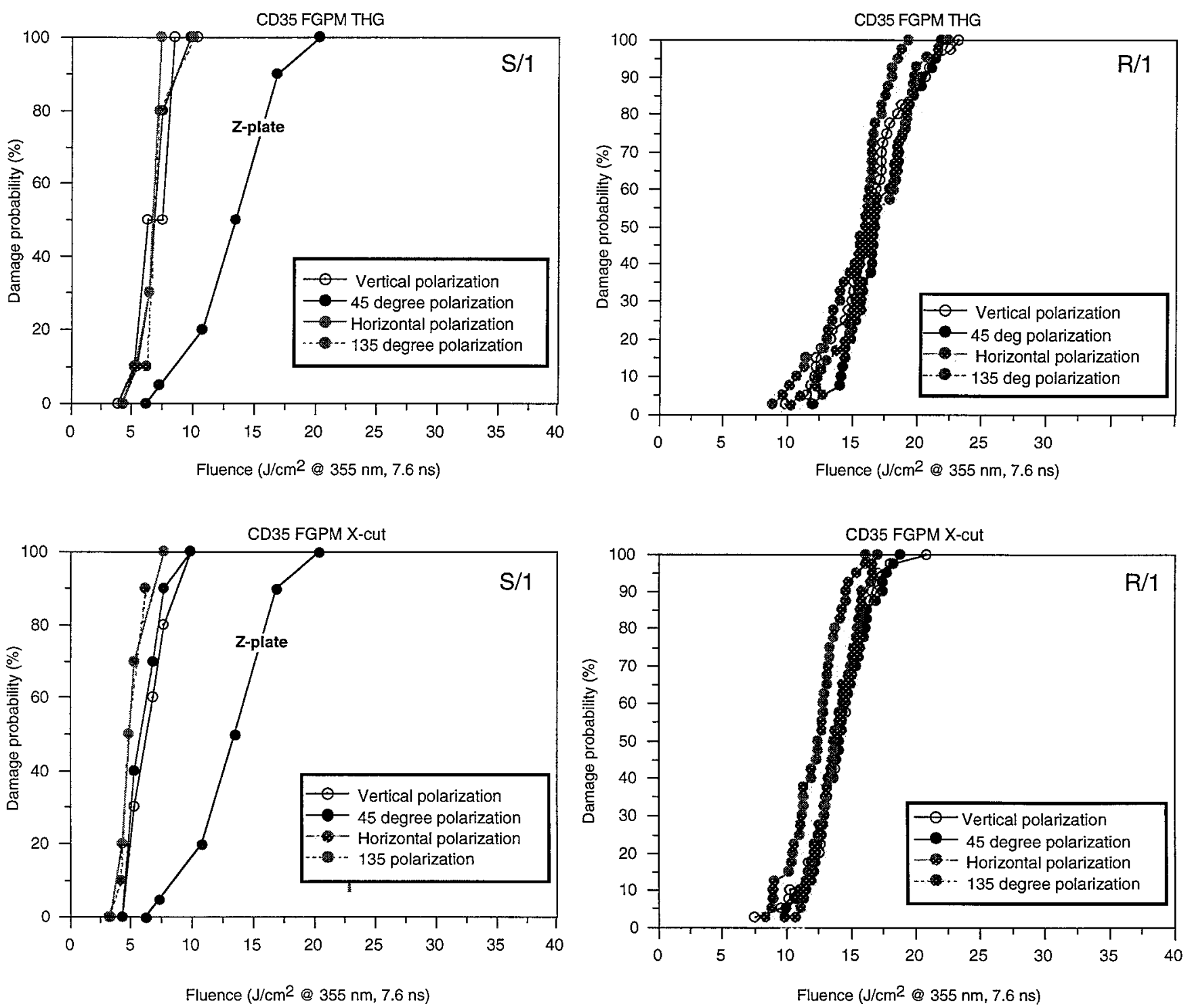

Figure 8. S/1 and R/1 damage curves in 4 different laser polarizations for CD-35 FGPM samples. The damage behavior of the samples is very similar to the BD-7 multifacet crystal and does not show polarization sensitivity for either the $S / 1$ or $R / 1$ tests.

We next explored the variation in damage curves by testing the last-grown pyramidal crystals. Given that we saw no variation among the different laser polarizations for the $S / 1$ and $R / 1$ tests on the first grown prism samples, only $R / 1$ tests were performed on the LGPY samples with the exception of the tripler sample. These test results are shown in Figure 9. 

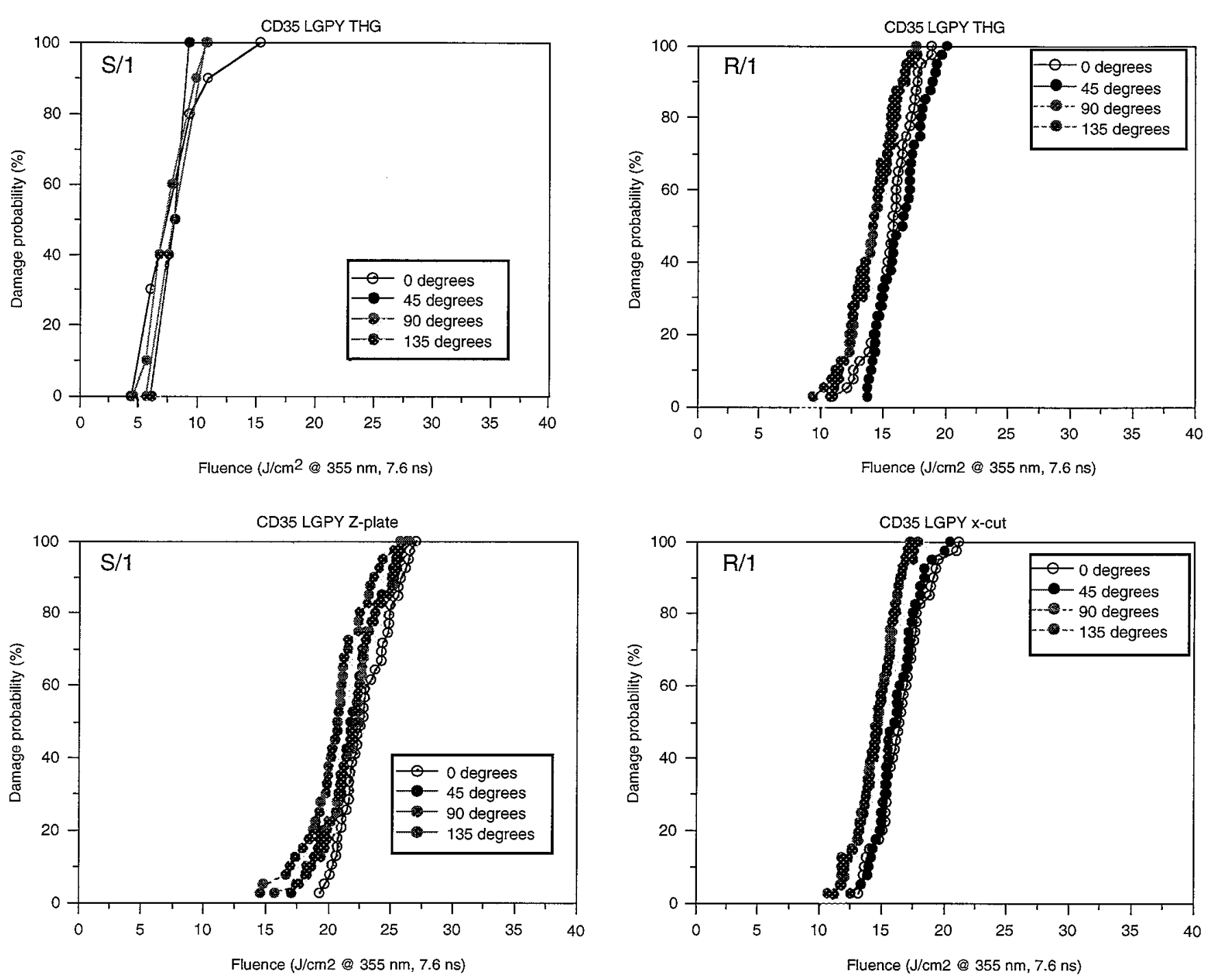

Figure 9. Results of polarization damage study on CD35 LGPY samples. There is no indication of polarization sensitivity in the data, and these curves are comparable to the FGPM case.

This data also shows that there is no polarization dependence for either the $\mathrm{S} / 1$ or $\mathrm{R} / 1$ cases. In addition, the individual sets of curves for x-, tripler- and z-cuts for the LGPM case are the same magnitude as their FGPR counterparts.

\subsubsection{Conventional-growth DKDP}

The NIF R\&D boule LL10 from Cleveland Crystals, Inc., provides the most comprehensive set of tests on the tripler vs. $z$ effect for conventional-growth DKDP. This boule was $70 \%$ deuterated. The difference between tripler and z-cuts is shown in Figure 10. The observed differences for both $\mathrm{S} / 1$ and $\mathrm{R} / 1$ curves are within the range observed for rapid-growth DKDP. 


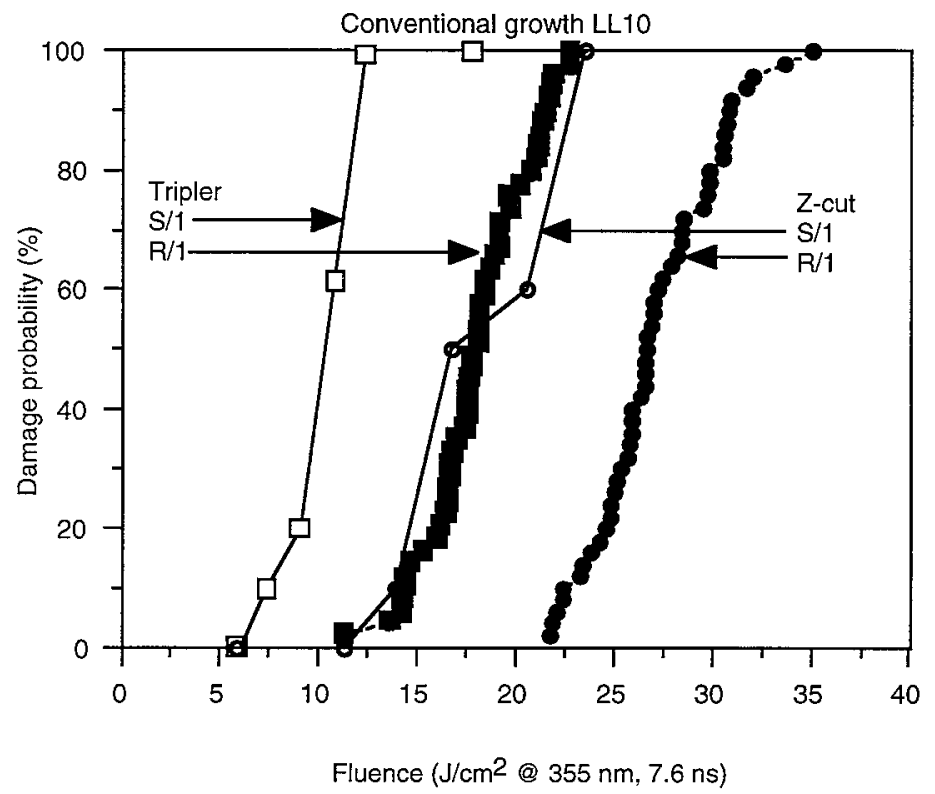

Figure 10. Damage probability curves for conventional-growth DKDP boule LL10. The reduction in tripler damage performance is quite typical.

\subsubsection{Conventional-growth KDP}

We have tested tripler and z-cut samples from only two samples of conventional-growth KDP, and none of rapid-growth KDP. The two conventional-growth samples from Cleveland Crystals, Inc., show approximately the same magnitude of drop in $50 \%$ damage fluence shown by the DKDP samples. Figure 11 shows the damage probability curves for the extremely high performance crystal KDP328 of Beamlet vintage.

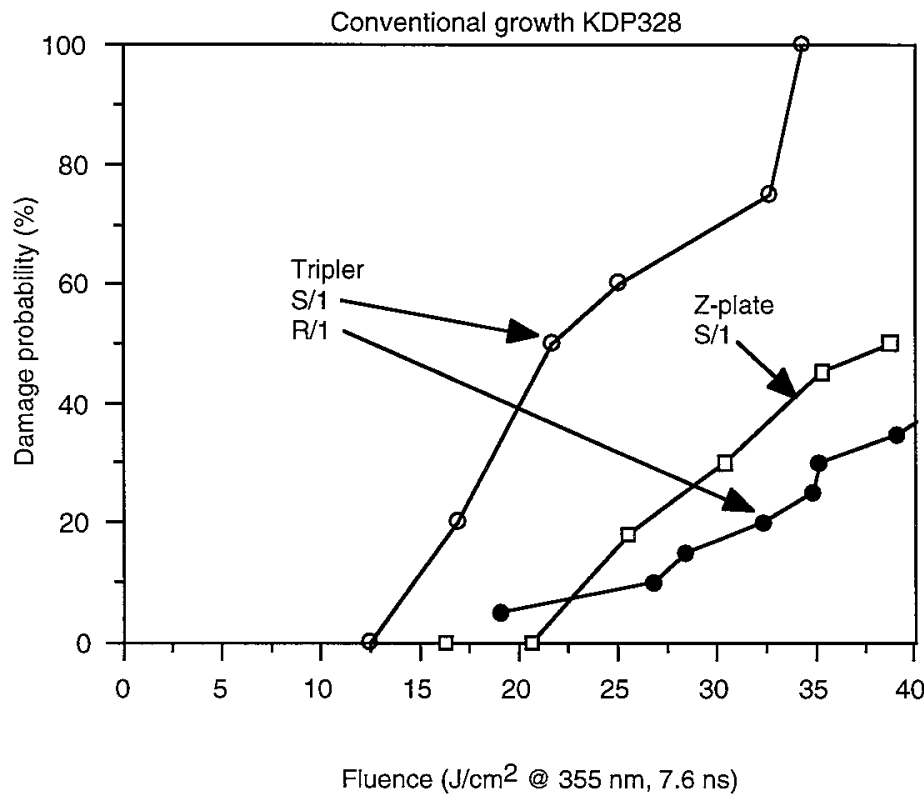

Figure 11. Damage probability curves for conventional-growth KDP328 samples. R/1 testing of the z-plate was not possible due to the high occurrence of surface damage. 
As in other cases, the drop in damage resistance for the triplers is typical. We could not perform an $\mathrm{R} / 1$ test on this sample because the surfaces were slightly contaminated when the side faces were polished. This contamination led to consistent surface damage at higher fluences during the $S / 1$ test.

\subsubsection{Compilation of results}

A summary table of all tripler- $z$ testing is given in Table 1 which shows that the average increase in $50 \%$ failure fluence from THG to $z$-cut for the $S / 1$ tests was $2.1 \pm 0.6$, while the $R / 1$ increase was only $1.5 \pm 0.3$. The overall variation in the $X$ or $T H G / z$ shifts for $\mathrm{S} / 1$ curves is large (ranging from 1.3 to 3.3), while the $\mathrm{R} / 1$ shifts are much more consistent, spanning the range of 1.2 to 2.3. The rapid-growth, large-tank DKDP boules BD-7 and CD35 have the largest difference between THG and z-cuts for the $\mathrm{S} / 1$ case, ranging from 2.2 to 3.3 . BD-7 also has the greatest shift for $\mathrm{R} / 1$ tests $(2.3)$, but the $\mathrm{R} / 1$ shifts for CD35 are typical of other boules.

The rapid-growth, small-tank DKDP boules grown at high temperature appear to have a slightly higher shift (2.1-2.7) than the low temperature boules (1.3-1.9) for the $\mathrm{S} / 1$ tests.

The $\mathrm{R} / 1$ shift for the conventional-growth samples is a very consistent $1.5 \mathrm{X}$, which appears to be nominal for all the crystals tested, whether rapid or conventionally grown. The S/1 curve shift is 1.7 for sample LL10. This is slightly below the average for all crystals tested. Since this was the only S/1 comparison for conventional-growth samples, we cannot say if this lower value is indicative of the performance of every conventional-growth, DKDP sample.

Much the same can be said for conventional-growth KDP samples. The R/1 shift for KDP355 of 1.2 is again lower than the average as is the $\mathrm{S} / 1$ result of $1.8 \mathrm{X}$ for $\mathrm{KDP} 328$.

Table 1. Damage test results on $\mathrm{z}$ - and tripler-cut and $\mathrm{x}$-cut crystals for $355 \mathrm{~nm}, 7.6 \mathrm{~ns}$ pulses. The number in parenthesis in the $\mathrm{z}$-plate column is the Z:THG 50\% failure fluence ratio. Samples names listed in italics are shown in the main body of report.

\begin{tabular}{|c|c|c|c|c|c|c|}
\hline \multirow[t]{2}{*}{ Sample } & \multirow[t]{2}{*}{ Material } & \multicolumn{2}{|c|}{ Z-plate $50 \%$ fluence } & \multicolumn{2}{|c|}{ Tripler 50\% fluence } & \multirow[t]{2}{*}{ Comments } \\
\hline & & $\mathrm{S} / 1\left(\mathrm{~J} / \mathrm{cm}^{2}\right)$ & $\begin{array}{c}\mathrm{R} / 1 \\
\left(\mathrm{~J} / \mathrm{cm}^{2}\right)\end{array}$ & $\begin{array}{c}\mathrm{S} / 1 \\
\left(\mathrm{~J} / \mathrm{cm}^{2}\right)\end{array}$ & $\begin{array}{c}\mathrm{R} / 1 \\
\left(\mathrm{~J} / \mathrm{cm}^{2}\right)\end{array}$ & \\
\hline \multicolumn{7}{|c|}{ Rapid-growth, small-tank boules } \\
\hline$D K D P 625$ & DKDP & -- & $26.5(1.4)$ & 12.5 & 18.4 & High temp \\
\hline$D K D P 636$ & DKDP & $40(1.9)$ & $43.7(1.5)$ & 21 & 29.9 & Low temp \\
\hline DKDP709 & DKDP & $31(1.5)$ & - & 21 & 30 & Low temp \\
\hline DKDP710 & DKDP & $17(2.3)$ & -- & 7.5 & 15 & High temp \\
\hline DKDP715 & DKDP & $20(2.1)$ & -- & 9.5 & 14.5 & High temp \\
\hline DKDP720 & DKDP & $27(1.9)$ & -- & 14 & 20 & Low temp \\
\hline DKDP727 & DKDP & $33(1.3)$ & -- & 25 & -- & Low temp \\
\hline DKDP728 & DKDP & $20(2.7)$ & -- & 7.5 & 15 & High temp \\
\hline \multicolumn{7}{|c|}{ Rapid-growth, large-tank boules } \\
\hline$B D 7$ & DKDP & $16(2.5)$ & $27(2.3)$ & 6.5 & 12 & \\
\hline$C D 35 F G P M$ & DKDP & $13(2.2)$ & -- & 6 & 16 & THG cut \\
\hline$C D 35 F G P M$ & DKDP & $13(3.3)$ & -- & 4 & 13 & X-cut \\
\hline CD35 LGPY & DKDP & -- & $21(1.5)$ & 7.5 & 14 & THG cut \\
\hline$C D 35 L G P Y$ & DKDP & - & $21(1.5)$ & -- & 14 & X-cut \\
\hline \multicolumn{7}{|c|}{ Conventional-growth, large tank boules } \\
\hline LL1-80\% & DKDP & -- & $29(1.5)$ & 8 & 19 & Beamlet \\
\hline LL1-70\% & DKDP & -- & $22(1.5)$ & -- & 15 & NIF R\&D \\
\hline$L L 10-70 \%$ & DKDP & $17(1.7)$ & $27(1.5)$ & 10 & 18 & NIF R\&D \\
\hline LL6-80\% & DKDP & & $26(1.4)$ & 8.5 & 18 & Beamlet \\
\hline $\begin{array}{c}\text { Conv } \\
\text { KDP355 }\end{array}$ & $\mathrm{KDP}$ & -- & $23(1.2)$ & 11 & 19 & \\
\hline $\begin{array}{c}\text { Conv } \\
K D P 328\end{array}$ & $\mathrm{KDP}$ & $39(1.8)$ & - & 22 & $>40$ & Beamlet \\
\hline
\end{tabular}




\section{DISCUSSION}

The data of Table 1 show that for every type of crystal tested there is a difference between tripler and z-cuts. The only type of crystal we have not tested for this effect is rapid-growth KDP. Given that we have seen the difference for conventionalgrowth $\mathrm{KDP}$, testing rapid-growth material is probably not necessary.

We currently have no satisfactory explanation for the dependence of damage resistance on beam propagation direction only. Simple absorption/thermal explosion models using non-spherical absorbers predict a polarization dependence in addition to a dependence on beam propagation direction. The dependence on beam propagation direction alone suggests some type of harmonic generation mechanism, but no satisfactory phase-matching conditions exist for $4 \omega, 5 \omega$ or $6 \omega$ (J. Auerbach, unpublished results, 2000). The only known limitation in that conclusion is the possibility that local disturbances to the crystal structure related to an absorbing particle could cause short-range phase matching conditions. Another possibility is that the orientational dependence is really one of damage growth rather than initiation. In other work ${ }^{6}$, we found that the size of the damage cavity depends on pulse duration, indicating that damage propagation is important. It has been suggested by Harry Tom (personal communication, 2000) that the piezoelectric properties of the crystal can affect the damage growth, hence detectability. However, no detailed investigation of this possibility has been done.

As a practical matter, these results indicate that future R\&D and QA testing of third harmonic generator material should be done only on tripler-cut samples. Studies are currently underway for pulse scaling, scatter, and obscuration behavior of tripler-cut material at $355 \mathrm{~nm}$. Although the primary pulse duration for the NIF will be $3 \mathrm{~ns}$, the laser will be operated from $<1-10 \mathrm{~ns}$. The current Zeus laser test system operates at $7.6 \mathrm{~ns}$, so pulse-scaling laws are needed to extrapolate these tests for the full range of NIF conditions ${ }^{6}$. In addition, an improved understanding is needed for how the standard $\mathrm{S} / 1$ and $\mathrm{R} / 1$ tests correspond to the more direct obscuration and low-angle scattering specifications for NIF operations.

As mentioned in the introduction, Yoshida et al. ${ }^{2}$ from the Institute of Laser Engineering, Osaka, Japan recently published a study of damage threshold differences in conventional-growth KDP as a function of laser wavelength, beam polarization and irradiation direction. They used a $1 \mathrm{~ns}$ Nd:YAG laser to test $\mathrm{x}$ - and z-cuts of KDP at $1 \omega, 2 \omega, 3 \omega$ and $4 \omega$. At $1 \omega$ they noted an increase in damage threshold by a factor of $\sim 1.7 \mathrm{X}$ for $\mathrm{z}$-cuts compared to $\mathrm{X}$-cuts and there was no polarization dependence. At $2 \omega$ they also noted an increase between $x$ - and z-cuts with the shift being approximately $1.6 \mathrm{X}$. They did not see a polarization dependence when rotating the sample by 90 degrees in a linearly polarized beam (starting with the beam polarized parallel to the $\mathrm{x}$-axis for a $\mathrm{z}$-cut or $\mathrm{z}$-axis for an $\mathrm{x}$-cut), but did see an increase of $\sim 1.8 \mathrm{X}$ in both $\mathrm{x}$ - and $\mathrm{z}$-cut thresholds when the sample was rotated by 45 degrees from its original position. They also repeated this test for a type II second harmonic generation crystal where they observed an increase in the damage threshold for the SHG producing geometry. This is in direct contradiction to results we have obtained earlier on Type I doublers ${ }^{3}$ where we observed no dependence between the ordinary and extraordinary polarizations when the crystal was prevented from doubling by angle detuning. But, when doubling was allowed the damage probability distribution dropped by 1.4-1.8X. In their experiments, Yoshida et al. did not think generation of $2 \omega$ light had an effect on their results.

At $3 \omega$ their experiments did not reveal any shift in the damage threshold between $x$ - and $z$-cuts (in disagreement with our work) or polarization (in agreement with our work). At $4 \omega$ they were unable to get reliable readings due to the onset of nonlinear processes such as SRS and SBS.

We believe that some of these discrepancies may be accounted for by differences in test method. In their work, the Osaka group used a short-focus geometry with a $30-\mu \mathrm{m}$ spot diameter to measure the damage threshold. It is well known that as beam size becomes smaller, sampling "extrinsic" defects such as impurity clusters, etc., occurs less often. Thresholds would be expected to go up as more "intrinsic" material was being sampled. In addition, small beams are well known to be difficult to characterize in terms of effective area, and slight fluctuations in energy, pulsewidth and beam shape can lead to large fluctuations in beam fluence that would be well in excess of the measurement precision quoted in their paper $( \pm 10 \%)$. In contrast, LLNL's best damage test systems can only produce fluences measurable to $\pm 15 \%$. Also, the Osaka work does not appear to take into account the uncertainty based on sampling statistics ${ }^{4}$, which adds an additional $\pm 15 \%$ for a typical 10 site damage threshold test on KDP. If these error bars are applied to their measurements, and considerations are made regarding the width of the underlying damage distribution, some of the results seen in their work are less convincing. 


\section{ACKNOWLEDGMENTS}

This work was performed under the auspices of the U.S. Department of Energy by the University of California Lawrence Livermore National Laboratory under contract No. W-7405-Eng-48. We gratefully acknowledge Stephen Maricle, Walter Sell and Dave Milam for damage testing in Zeus and OSL and Sue Locke, Randy Floyd and Ruth Hawley-Fedder and Cleveland Crystals, Inc. for providing samples.

\section{REFERENCES}

1. M. Runkel, M. Yan, J. De Yoreo, N. Zaitseva, "The effect of impurities and stress on the damage distributions of rapidly grown KDP crystals," SPIE Proceedings, Volume 3244, 211-223, 1997

2. H. Yoshida, T. Jitsuno, H. Fujita, M. Nakatsuka, M. Yoshimura, T. Sasaki, K. Yoshida, "Investigation of bulk laser damage in KDP crystal as a function of irradiation direction, polarization and wavelength," Applied Physics B, Volume $70,195-201,2000$

3. M. Runkel, S.Maricle, R. Torres, J. Auerbach, R. Floyd, R. Hawley-Fedder, A. Burnham, "The effect of thermal annealing and second harmonic generation on bulk damage performance of rapid-growth, KDP doublers at $1064 \mathrm{~nm}$," SPIE Proceedings for this symposium

4. M. Runkel, "Monte Carlo simulation of the R/1 automated damage test," SPIE Proceedings, Volume 3578, 277-289, 1998

5. A. Burnham, M.Runkel, R. Hawley-Fedder, L. Carman, R. Torres, P. Whitman, "Low-temperature growth of DKDP for improved $3 \omega$-damage resistance," SPIE Proceedings for this symposium

6. M. Runkel, A. Burnham, D. Milam, W. Sell, M. Feit, A. Rubenchik, "The results of pulse-scaling experiments on rapidgrowth DKDP triplers using the Optical Sciences Laser at $351 \mathrm{~nm}$," SPIE Proceedings for this symposium 